\title{
Modelling of a Generation System with Coiled Rotor Synchronous Generator for Renewable Energy
}

\author{
Souhir Tounsi \\ National School of Electronics and Telecommunications of Sfax, SETIT-Research Unit, Sfax University, Sfax, Tunisia \\ Email address: \\ souhir.tounsi@enetcom.rnu.tn
}

\section{To cite this article:}

Souhir Tounsi. Modelling of a Generation System with Coiled Rotor Synchronous Generator for Renewable Energy. International Journal of Electrical Components and Energy Conversion. Vol. 1, No. 3, 2015, pp. 75-82. doi: 10.11648/j.ijecec.20150103.12

\begin{abstract}
In this paper we present a modeling approach to a system for renewable energy generating including the loss of all the generation chain. The choice of the energy generation chain components is conducted taking account of the possibility to achieve high current to recover high power in the one hand and the simplicity of the chain structure and of its components in order to reduce the cost of production in the other hand. Indeed, a synchronous motor wit coiled rotor and reduced production cost is chosen for the electric energy generation. To enable continuous energy recovery, excitation current is increased at low speeds and reduced at high speeds to prevent over current problem. The implementation of the global model in the simulation environment Matlab Simulink has led to very good results of simulations encouraging the industrialization process of this chain.
\end{abstract}

Keywords: Coiled Rotor Generator, Rectifier, Modeling, Battery, Recovered Energy

\section{Introduction}

This paper present a parameterized model of the generation chain of renewable energy. This step is conducted in parallel with a synchronous generator design stage dedicated to the generation of energy [1-3].

Energy generation chain is subdivided into modules and each module is modeled at Matlab-Simulink simulation environment. The coupling of different models leads to overall power generation chain model.

This paper is mainly articulated around the following points:

- A presentation of the model approach to the different modules of the energy generation chain.

- Implementation of the global model in the Matlab Simulink simulation environment.

- A description of the simulations results.

\section{Conversion Chain Structure}

Conversion chain (figure 1) has a propeller to recover the energy generated by wind, this mechanical energy is converted into an alternating electrical energy via a gear speed amplifier and a permanent magnets synchronous generator. The electrical energy developed is also converted into DC power through a three-phase rectifier.

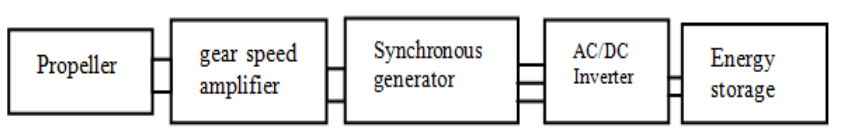

Fig. 1. Power chain structure.

\section{Model of the Battery}

The energy accumulator comprises batteries in parallel with supper-capacity to increase storage capacity. The Simulink model of the battery is shown in Figure $2[1,2]$.

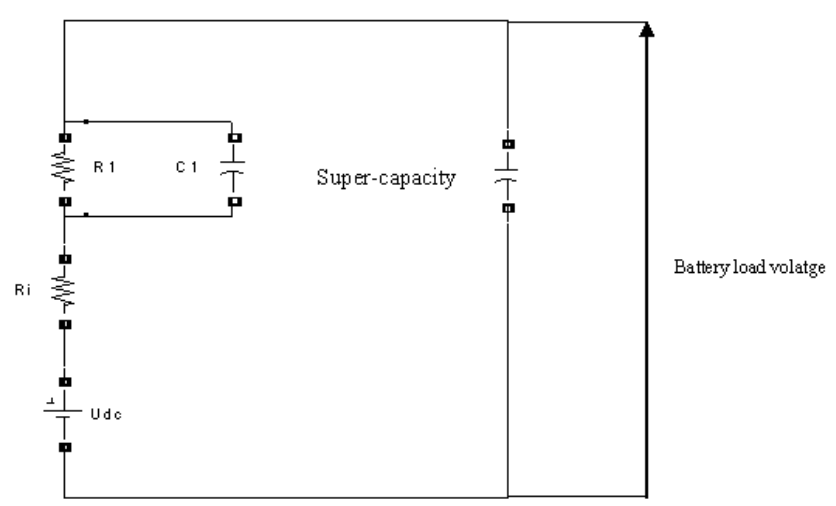

Fig. 2. Model simulink of the batteries.

$\mathrm{C} 1$ is a capacity to take into account the transitional 
arrangements.

$\mathrm{Ri}$ is the internal resistance of the battery.

\section{Equations of Motion}

The equation that governs the motion of the rotating parts of the energy generation chain is derived from the fundamental dynamics relationship:

$J \times \frac{d \Omega}{d t}=T_{m}-r_{d} \times\left(T_{e m}-\operatorname{sgn}\left(T_{e m}\right) \times T_{m e c}-\operatorname{sgn}\left(T_{e m}\right) \times T_{f e r}\right)$

Where $\mathrm{J}$ is the moment of inertia of the rotating parts, $r$ $\mathrm{d}$ is the speed amplification ratio, Tm is the torque impos ed on the motor shaft caused by the movement of wind, $T$ em is the electromagnetic torque, Tmec is the torque due the mechanical losses and Tfer is the torque due to iron 1 osses [4-12].

$$
\mathrm{T}_{\mathrm{m}}=\frac{1.918 \times \mathrm{R}_{\mathrm{p}}^{2} \times \mathrm{V}_{\mathrm{vent}}^{3}}{\Omega}
$$

$$
\mathrm{T}_{\mathrm{em}}=\frac{1}{\Omega} \sum_{\mathrm{i}=1}^{3} \mathrm{e}_{\mathrm{i}} \times \mathrm{i}_{\mathrm{i}}
$$

Where ei and ii are respectively the induced electromotive force and the current of the phase $i$.

Where 1.918 is a coefficient that depends on the kinetic energy of the wind and pale properties, $\mathrm{Rp}$ is the pale ray and Vvent is the wind speed.

The implementation of this equation in the environment MATLAB / Simulink is illustrated in Figure 3:

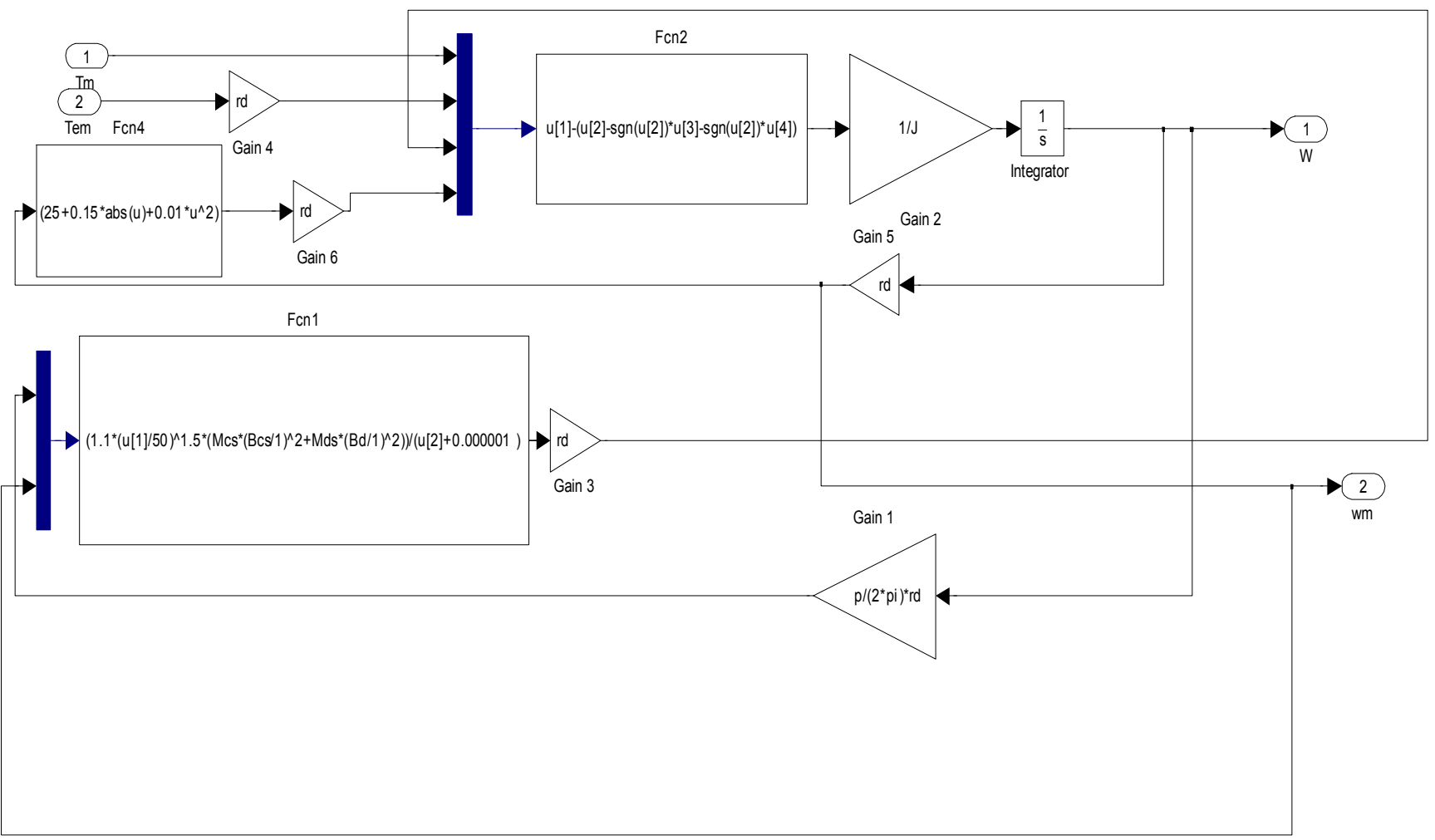

Fig. 3. Simulink model of the motion equation.

\section{Model Electromotive Forces}

The three induced electromotive forces are estimated from the following three equations [4-12]:

$$
\begin{aligned}
& \mathrm{e}_{1}=\frac{2}{3} \times \mathrm{K}_{\mathrm{e}} \times \Omega \times \cos \left(\mathrm{p} \times \Omega \times \mathrm{t}+\frac{\pi}{2}\right) \\
& \mathrm{e}_{2}=\frac{2}{3} \times \mathrm{K}_{\mathrm{e}} \times \Omega \times \cos \left(\mathrm{p} \times \Omega \times \mathrm{t}-\frac{2 \times \pi}{3}+\frac{\pi}{2}\right)
\end{aligned}
$$

$$
\mathrm{e}_{3}=\frac{2}{3} \times \mathrm{K}_{\mathrm{e}} \times \Omega \times \cos \left(\mathrm{p} \times \Omega \times \mathrm{t}-\frac{4 \times \pi}{3}+\frac{\pi}{2}\right)
$$

Where Ke is the electromotive constant and $\Omega$ is the angular velocity of the generator.

The Simulink model of the electromotive forces is illustrated by the figure 4 : 


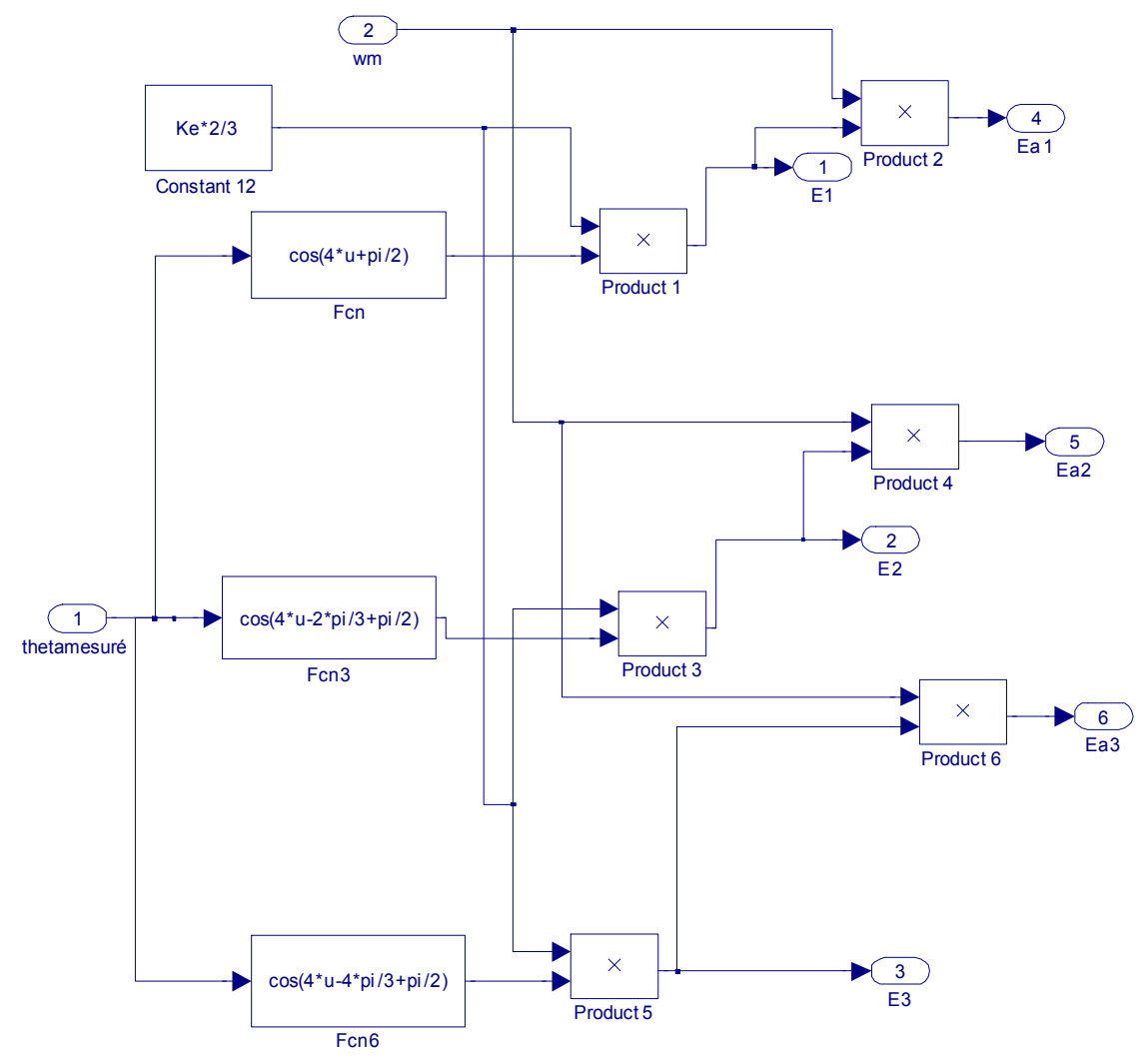

Fig. 4. Simulink Model electromotive forces.

\section{Model of Generator-Rectifier Unit}

The generator phase voltages are given by the following relationships [4-12]:

$$
\begin{gathered}
\mathrm{v}_{1}=\mathrm{R} \times \mathrm{i}_{1}+(\mathrm{L}-\mathrm{M}) \times \frac{\mathrm{di}_{1}}{\mathrm{dt}}+\mathrm{e}_{1} \\
\mathrm{v}_{2}=\mathrm{R} \times \mathrm{i}_{2}+(\mathrm{L}-\mathrm{M}) \times \frac{\mathrm{di}_{2}}{\mathrm{dt}}+\mathrm{e}_{2}
\end{gathered}
$$

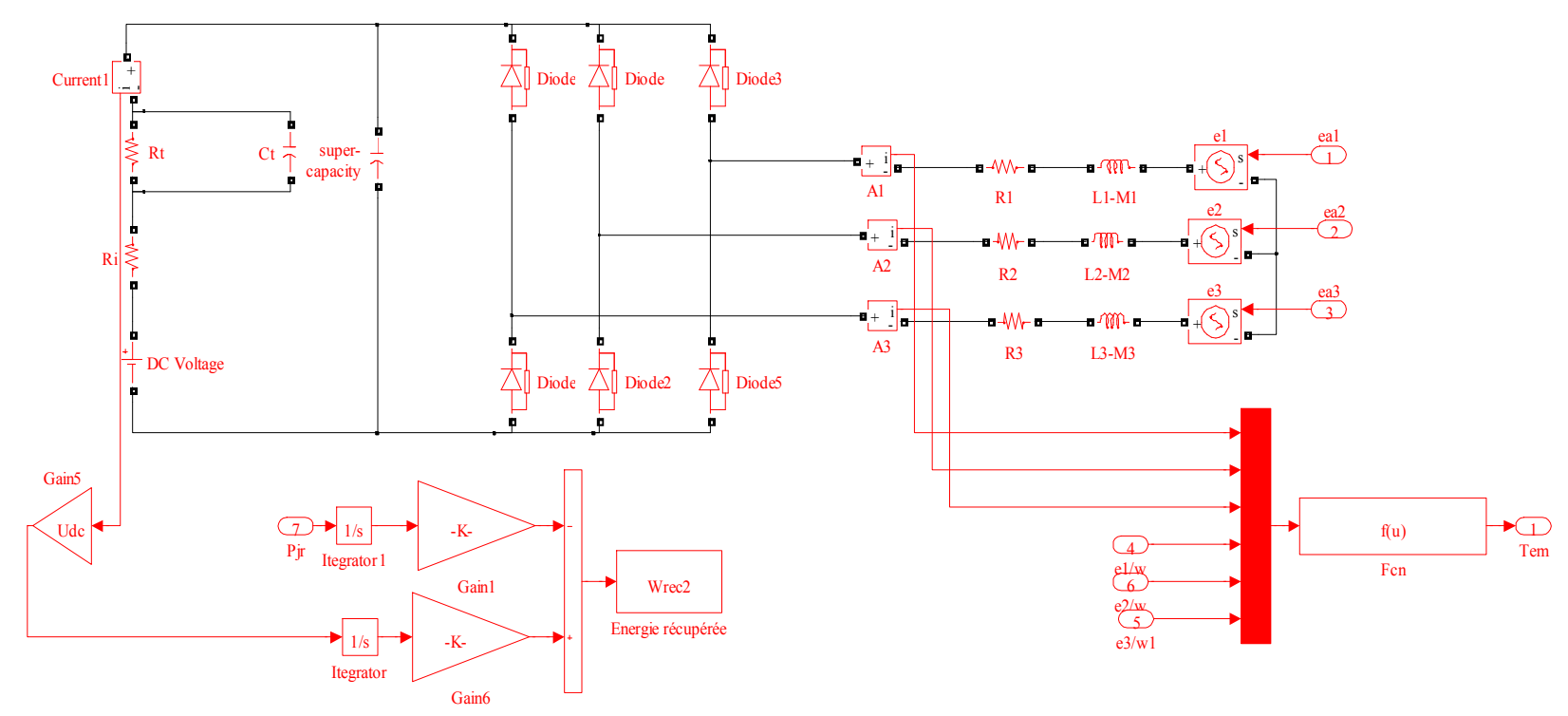

Fig. 5. Simulink model of the generator-rectifier.
Where $\mathrm{R}, \mathrm{L}$ and $\mathrm{M}$ are respectively the phase resistance, phase inductance and phase mutual inductance.

The three phase voltages are converted into a DC voltage through a PD3 rectifier. The rectified voltage is filtered by a capacitor. The output voltage of the rectifier attack directly the batteries for recharging:

Simulink model of the generator-rectifier assembly is shown in Figure $5[1,2]$. 


\section{Excitation System}

The optimization system of the excitation current (figure 6) makes it possible to increase the excitation current for low speed for continuous recovery of energy on the one hand and on the other hand reduces the excitation current for high speeds to avoid the burning problem of energy generation system.

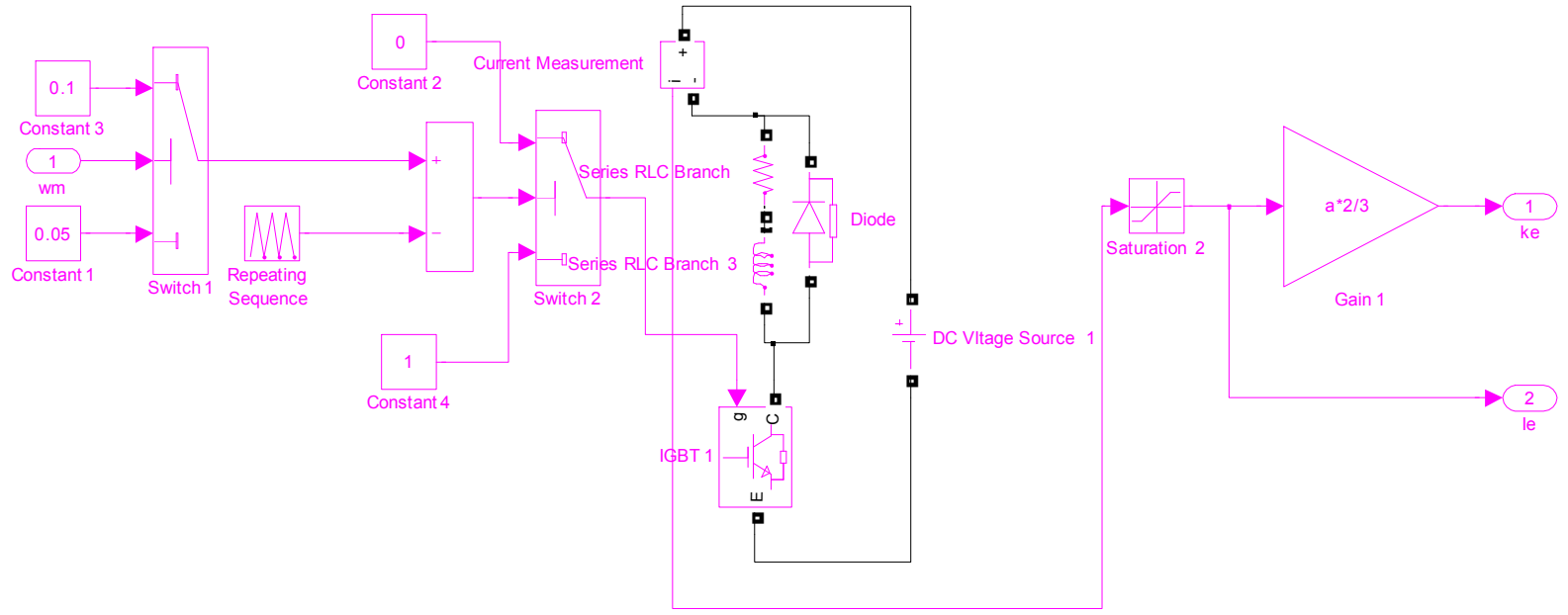

Fig. 6. Simulink of the excitation system.

\section{Global model of the Power Chain}

The global model of the energy generation system is based on the connection of the different Simulink models of the chain components make up this chain according to Figure 7 [1-3]:

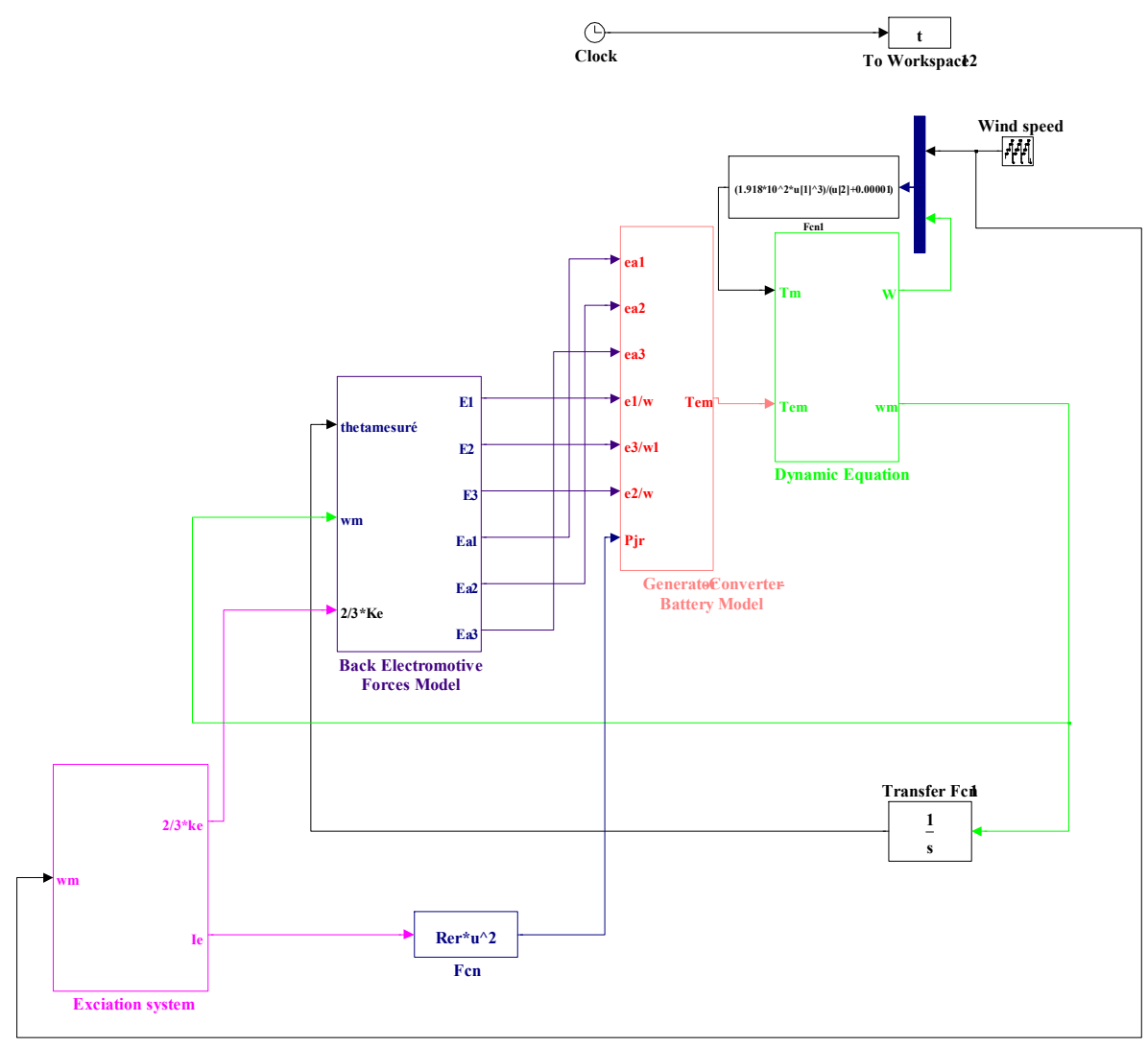

Fig. 7. Simulink model of global energy generation chain. 


\section{Description of Simulation Results}

Figure 8 shows the evolution of the excitation current:

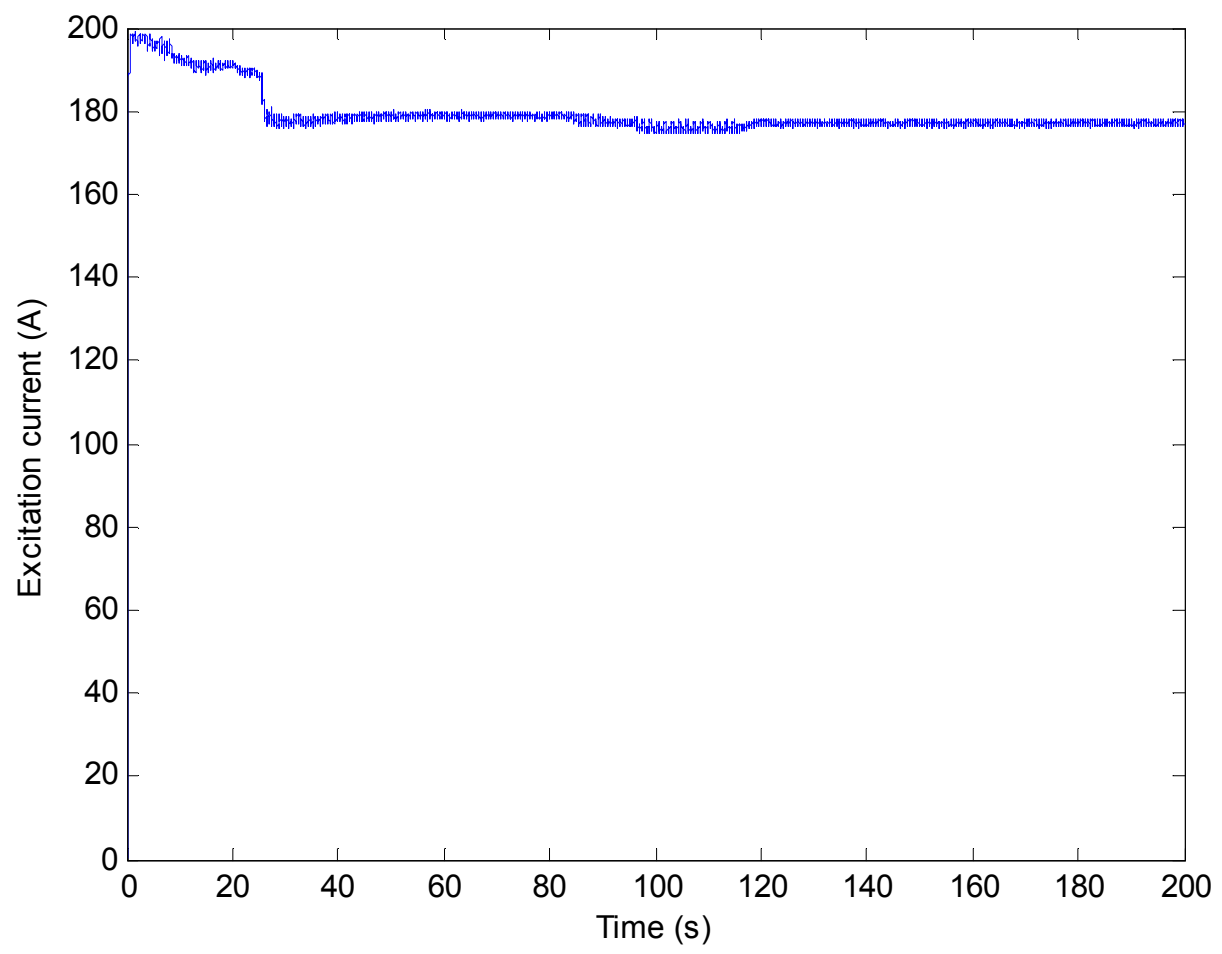

Fig. 8. Evolution of the excitation current.

Excitation current present its maximal values at low speed. generator:

Figure 9 shows the electromotive forces induced by the

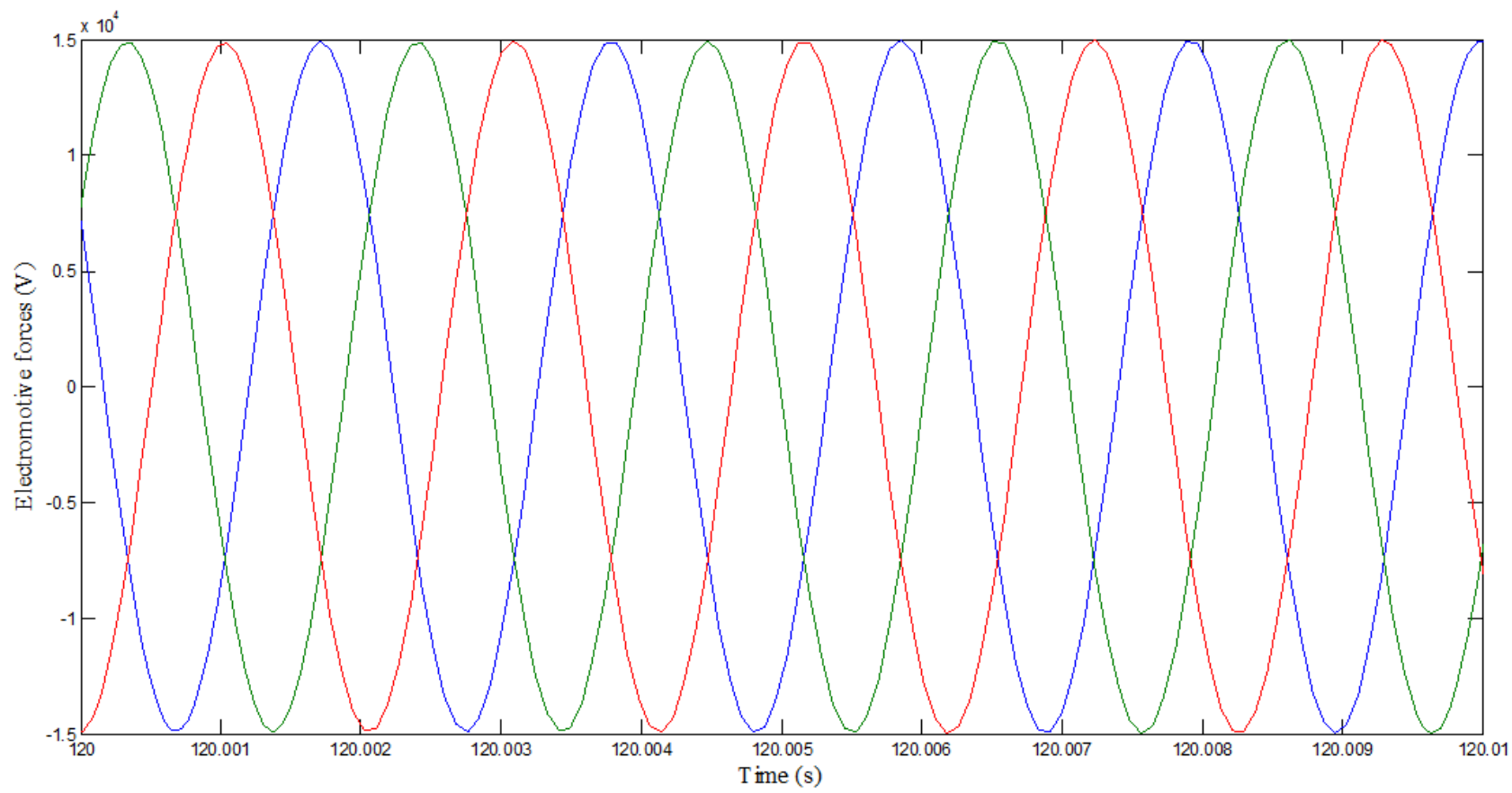

Fig 9. Induced electromotive forces.

The amplitude of the electromotive forces is relatively high, which is explained by the insert made of a gear amplifier with amplifying ratio $\mathrm{rd}=8$. This is to compensate the drop of phase voltages of the generator at battery charging phase. 
Figure 10 illustrates the phase voltages of the generator:

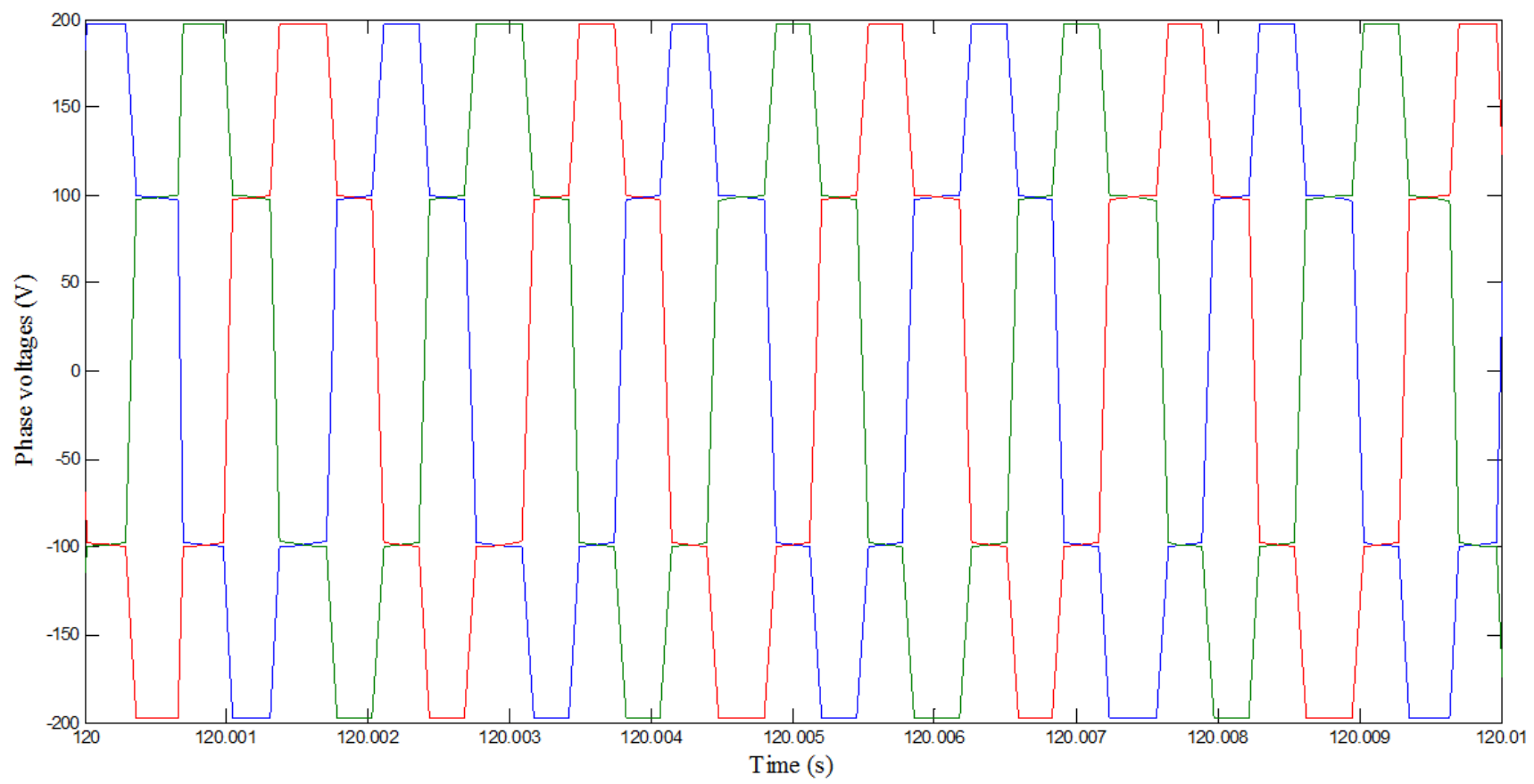

Fig. 10. Phase voltages generator.

The amplitude of the phase voltages is reduced relative to the amplitude of the electromotive forces since the voltage drop across the phase resistance is important.
Figure 11 illustrates the phase currents begun by the generator:

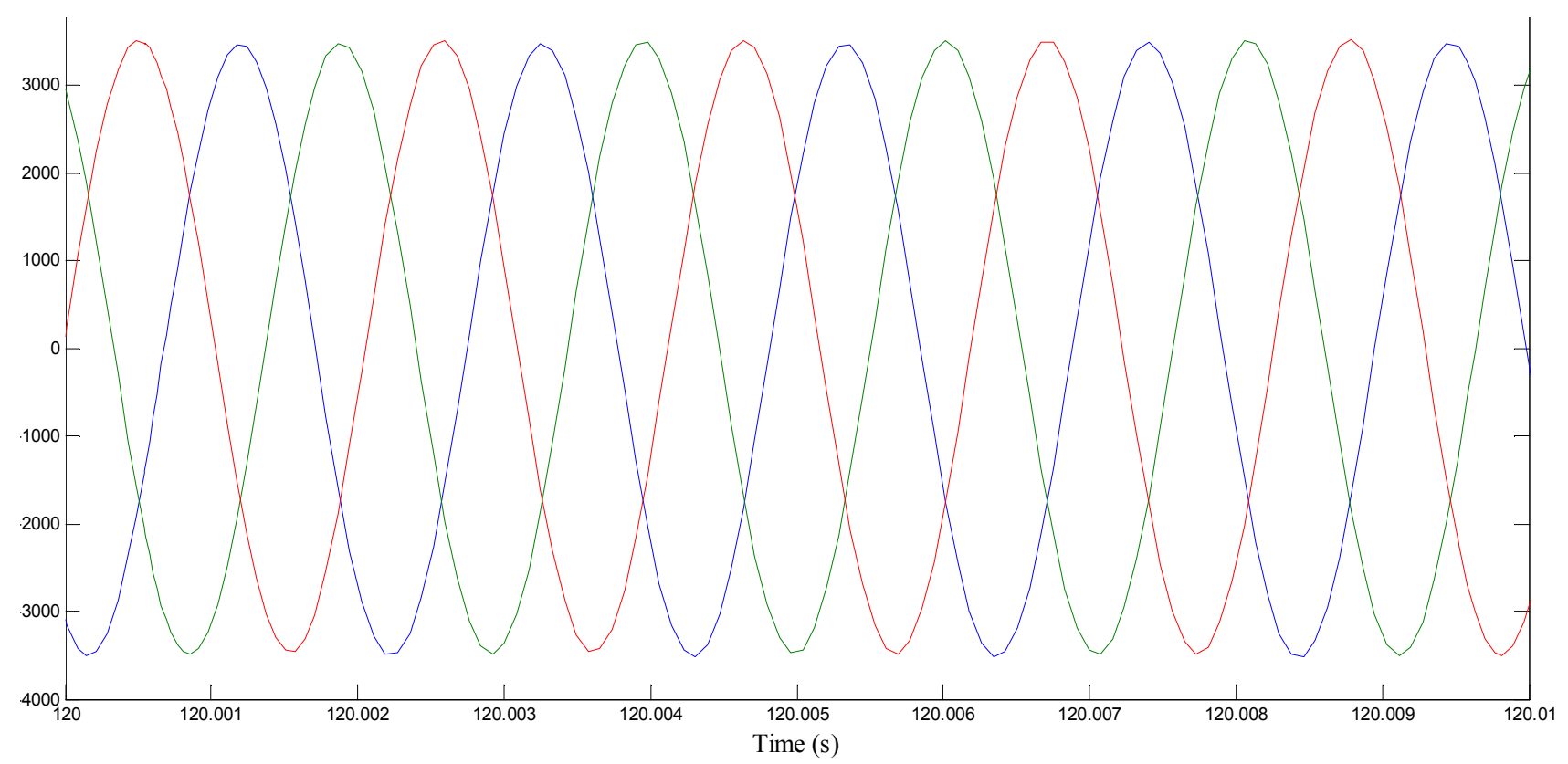

Fig. 11. Phase currents of the generator.

The amplitude of the generator phase currents depends primarily on the internal resistance of the battery and of the rectified voltage.

The battery charging voltage is shown in Figure 12: 


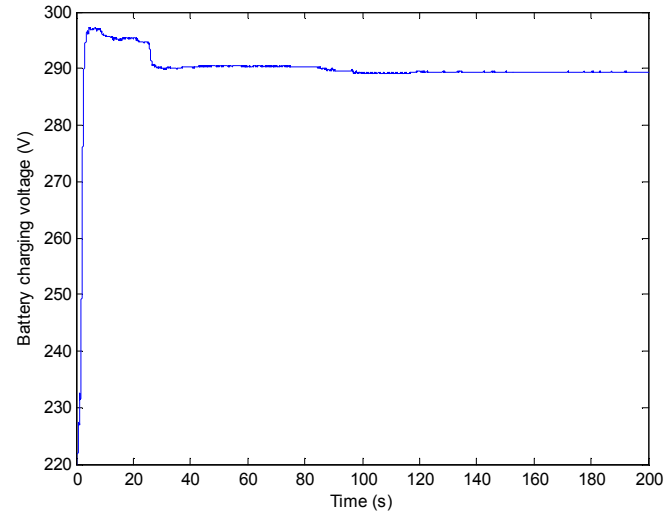

Fig. 12. Battery charging voltage.

This voltage is maintained continuously since it is applied directly to a super-capacity. The amplitude of this voltage allows for continuous charging of the batteries as the nominal battery voltage is $220 \mathrm{~V}$ significantly below to this voltage.

The power generated by the wind and the power recovered by the batteries are illustrated in Figure 13:

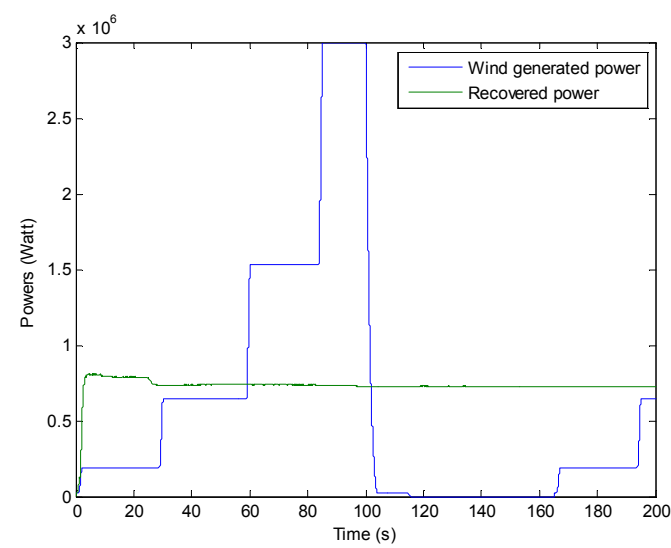

Fig. 13. Wind Power and power recovered by the battery.

This figure watch that the power transferred to the batteries is lower than that developed by the wind, which is explained by the different losses of energy generation chain.

The current charging the batteries is shown in Figure 14:

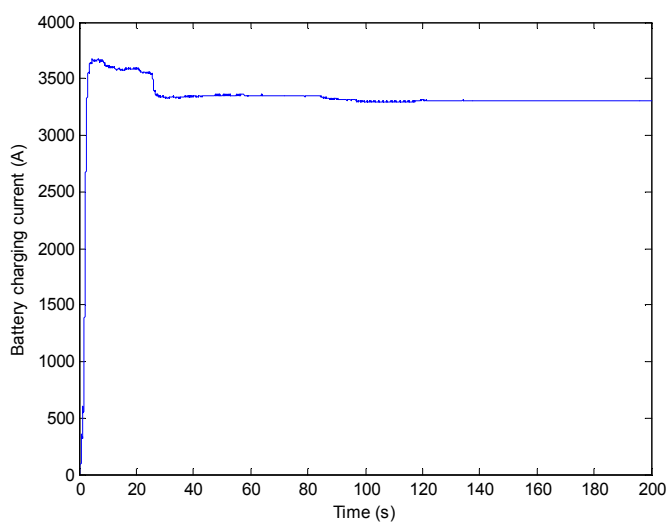

Fig. 14. Battery charging current.
The energy recovered by the batteries is shown in Figure 15:

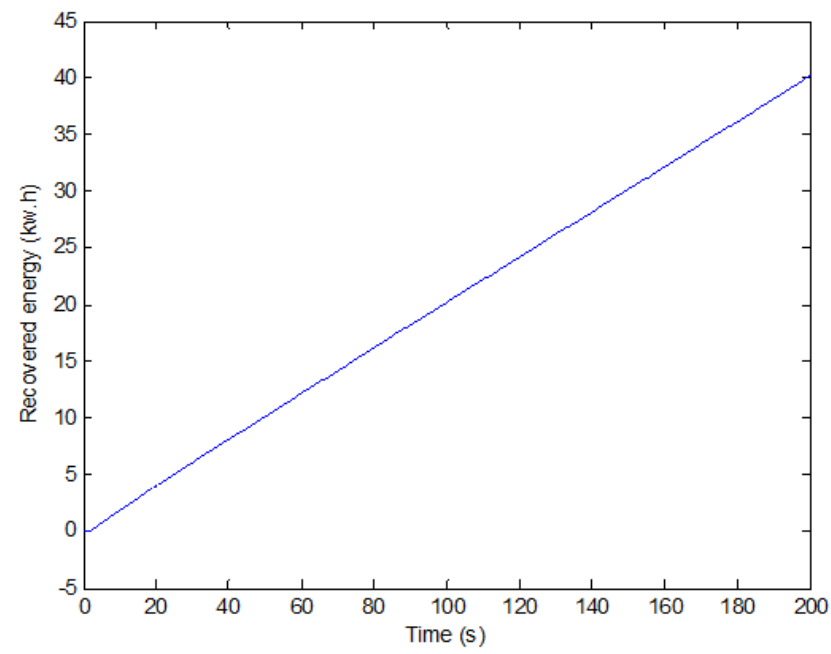

Fig. 15. The energy recovered by the batteries.

This energy is approximately $40 \mathrm{kw} . \mathrm{h}$, important value which validates the performance of the designed generation chain.

\section{Conclusion}

In this paper we have described a modeling approach of a renewable energy generation with coiled rotor synchronous generator chain implanted under the Matlab Simulink simulation environment. This approach is consistent with optimization algorithms, for example, the recovered energy. Simulation results are with good scientific level and validate the synchronous generator design approach dedicated to the generation of renewable energy. The system studied can be used in charging stations for electric cars.

\section{References}

[1] Souhir Tounsi, Design and Optimization of Axial Flux Brushless DC Generator Dedicated to Generation of Renewable Energy, American Journal of Electrical Power and Energy Systems. Special Issue:Design and Monitoring of Renewable Energy Systems (DMRES). Vol. 4, No. 3-1, 2015, pp. 1-5. doi: 10.11648/j.epes.s.2015040301.11.

[2] Wiem Nhidi, Souhir Tounsi, Mohamed Salim Bouhlel, Design and Modeling of a Synchronous Renewable Energy Generation System, American Journal of Electrical Power and Energy Systems. Special Issue:Design and Monitoring of Renewable Energy Systems (DMRES). Vol. 4, No. 3-1, 2015, pp. 6-11. doi: 10.11648/j.epes.s.2015040301.12.

[3] Mariem Ben Amor, Souhir Tounsi, Mohamed Salim Bouhlel, Design and Optimization of Axial Flux Brushless DC Motor Dedicated to Electric Traction, American Journal of Electrical Power and Energy Systems. Special Issue:Design, Optimization and Control of Electric Vehicles: (DOCEV). Vol. 4, No. 2-1, 2015, pp. 42-48. doi: $10.11648 /$ j.epes.s.2015040201.16. 
[4] Chaithongsuk, S., Nahid-Mobarakeh, B., Caron, J., Takorabet, N., \& Meibody-Tabar, F. : Optimal design of permanent magnet motors to improve field-weakening performances in variable speed drives. Industrial Electronics, IEEE Transactions on, vol 59 no 6, p. 2484-2494, 2012.

[5] Rahman, M. A., Osheiba, A. M., Kurihara, K., Jabbar, M. A., Ping, H. W., Wang, K., \& Zubayer, H. M. : Advances on single-phase line-start high efficiency interior permanent magnet motors. Industrial Electronics, IEEE Transactions on, vol 59 no 3, p. 1333-1345, 2012.

[6] C.C Hwang, J.J. Chang : Design and analysis of a high power density and high efficiency permanent magnet DC motor, Journal of Magnetism and Magnetic Materials, Volume 209, Number 1, February 2000, pp. 234-236(3)-Publisher: Elsevier.

[7] MI. Chunting CHRIS : Analytical design of permanent-magnet traction-drive motors" Magnetics, IEEE Transactions on Volume 42, Issue 7, July 2006 Page(s):1861 - 1866 Digital Object Dentifier 10.1109/TMAG.2006.874511.

[8] S.TOUNSI, R.NÉJI, F.SELLAMI : Conception d'un actionneur à aimants permanents pour véhicules électriques, Revue Internationale de Génie Électrique volume 9/6 2006 pp.693-718.
[9] Sid Ali. RANDI : Conception systématique de chaînes de traction synchrones pour véhicule électrique à large gamme de vitesse. Thèse de Doctorat 2003, Institut National Polytechnique de Toulouse, UMRCNRS N 5828.

[10] C. PERTUZA : Contribution à la définition de moteurs à aimants permanents pour un véhicule électrique routier. Thèse de docteur de l'Institut National Polytechnique de Toulouse, Février 1996

[11] S. TOUNSI, R. NEJI and F. SELLAMI: Mathematical model of the electric vehicle autonomy. ICEM2006 (16th International Conference on Electrical Machines), 2-5 September 2006 Chania-Greece, CD: PTM4-1.

[12] R. NEJI, S. TOUNSI, F. SELLAMI: Contribution to the definition of a permanent magnet motor with reduced production cost for the electrical vehicle propulsion. Journal European Transactions on Electrical Power (ETEP), Volume 16, issue 4, 2006, pp. 437-460. 